\title{
PENGETAHUAN MASYARAKAT KALIAMOK - MALINAU TENTANG TUMBUHAN OBAT
}

\section{The Knowledge of Kaliamok-Malinau Local Community About Medicinal Plants}

\author{
Ade Setiawan $^{\mathrm{a}}$, Fadhlan Muchlas Abrori ${ }^{\mathrm{a}}$
}

\begin{abstract}
Abstrak
Tujuan penelian ini adalah untuk mengetahui perbedaan pengetahuan antara masyarakat generasi tua dan generasi muda terkait tumbuhan obat. Terdapat perbedaan pengetahuan antara generasi muda dan generasi tua terkait tumbuhan obat. Berdasarkan data yang diperoleh generasi tua setidaknya masih menggunakan 12 spesies tumbuhan obat dalam kehidupan sehari-hari. Sementara generasi muda hanya menggunakan 7 spesies.
\end{abstract}

\section{Kata kunci}

Pengetahuan Masyarakat, Tumbuhan Obat

\begin{abstract}
The purpose of this study was to determine the differences in knowledge between the older generation and the younger generation regarding medicinal plants. There are differences in knowledge between the younger and older generations regarding medicinal plants. Based on data obtained by the older generation, at least 12 species of medicinal plants are still used in their daily life. Meanwhile, the younger generation only uses 7 species.
\end{abstract}

\section{Keywords}

Community's Knowledge, Medicinal Plants

\section{Pendahuluan}

Setiap suku di Indonesia memiliki kebudayaan yang khas dalam pemanfatan tumbuhan di lingkungan sekitarnya. Salah satu cara pemanfaatannya dengan menggunakan tumbuhan tersebut menjadi obat herbal. Lambat laun kebiasaan dan pengalaman mereka dalam pemanfaatan tumbuhan menjadi sebuah pengetahuan tradisional. Pengetahuan tradisional ini nantinya akan diturunkan kepada generasi selanjutnya oleh generasi yang lebih tua. Pewarisan 


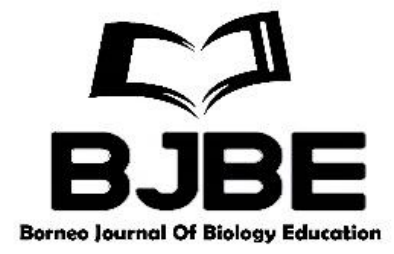

pengetahuan ini tetap menjaga tradisi dan kebiasaan dalam masyarakat tetap terlaksana dari generasi ke generasi.

Secara tidak langsung pengetahuan terkait tumbuhan obat ini mengalami perubahan, karena perubahan interaksi manusia dengan lingkungannya (Metananda, 2011). Secara garis besar, ilmu pengobatan herbal di masyarakat didasarkan pada sebab terjadinya penyakit, dan dibagi ke dalam dua kategori, yaitu etiologi personalistik, dan etiologi naturalistik. Etiologi personalistik, menyatakan penyakit sebagai gangguan mahluk halus seperti jin, roh dan hantu (Syukur et al,. 2011, Ilhadi, 2016). Sementara itu etiologi naturalistik menyatakan bahwa penyakit berasal dari gangguan pada tubuh manusia itu sendiri, atau terkait dengan lingkungannya (Saifrudin dan Kasniyah, 2013).

Pengetahuan lokal terkait tumbuhan obat di masyarakat, khususnya di kalangan generasi muda saat ini sudah banyak mengalami pergeseran. Generasi muda banyak yang tida mengetahui tumbuhan obat lokal yang digunakan generasi sebelumnya. Penelitian oleh Ani et al., (2018) terkait pengetahuan tumbuhan obat di daerah Sumbawa setidaknya hanya 10 responden yang memiliki pengetahuan sangat baik terkait tumbuhan obat. Penelitian serupa oleh Atmojo (2013) terkait pengetahuan tanaman obat di Blora, didapatkan data bahwa masyarakat hanya familiar dengan satu jenis tumbuhan obat.

Penelitian terkait jenis tumbuhan obat telah dilakukan pada Suku Dayak Lundayeh, Desa Kaliamok, Malinau (Setiawan et al., 2019). Namun, untuk penelitian lebih lanjut perlu juga dilakukan penelitian terkait pengetahuan tumbuhan obat pada generasi muda dan generasi muda. Hasil penelitian ini akan sangat berguna untuk penelitian lanjutan terkait etnobotani, terutama terkait pengenalan tumbuhan obat pada generasi muda.

\section{Material dan metode}

Penelitian ini merupakan penelitian lanjutan dari penelitian Setiawan et al., (2019) terkait kajian etnobotani tumbuhan obat di Suku Dayak Lundayeh, Desa Kaliamok Malinau. Penelitian dilanjutkan untuk mengetahui pengetahuan masyarakat terkait tumbuhan. Penelitian menggunakan angket yang mengacu kepada Suryadarma (2008), angket digunakan untuk mendapatkan informasi dari pengetahua masyarakat yang berbeda usia mengenai tumbuhan yang disusun mulai dari pernah mendengar, melihat dan menggunakan sebagai obat.

Populasi dalam penelitian ini adalah seluruh masyarakat Desa Kaliamok. Sampel penelitian ini adalah 20 orang masyarakat yang dibagi menjadi dua kelompok masyarakat yaitu: generasi muda (usia 15-35 tahun), dan generasi tua (usia > 36 tahunn). Pengambilan sampel dilakukan dengan menggunakan teknik purposive sampling yaitu dengan mempertimbangkan bahwa responden adalah 1. Masyarakat Desa Kaliamok, 2. Suku Dayak Lundayeh, 3. Usia dalam cakupan kedua kelompok. Peneliti menentukan jumlah sampel menggunakan panduan Gay dan Diehl yaitu sampel minimumnya adalah 10\% dari populasi (Nurraini dan Tabba, 2013).

Lembar angket pengetahuan masyarakat yang dibuat berisi pertanyaan mengenai tumbuhan obat mulai dari pernah mendengar, melihat, mengkonsumsi dan menggunakan sebagai obat. Uji Mann-Whitney digunakan untuk mengetahui perbedaan pengetahuan masyarakat antar kelompok usia yang berbeda. Data untuk Uji beda Mann-Whitney diambil 


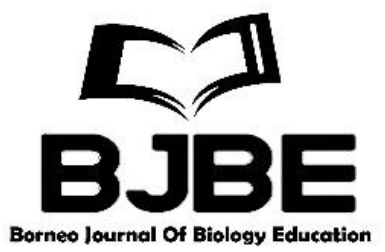

Vol. 2 No. 1, 2020; pp. 49-54

P-ISSN: 2715-6826 (print); E-ISSN: 2714-6073 (online)

Received: $12 / 07 / 2019$

Revised: 09/08/2019

Accepted: 15/10/2019

dari skor angket pengetahuan masyarakat kemudian data tersebut diolah menggunakan bantuan softwere SPSS 22 untuk memperoleh ada atau tidaknya perbedaan pengetahuan masyarakat mengenai tumbuhan obat dari generasi muda sampai generasi tua.

\section{Hasil dan Diskusi}

Pengetahuan mengenai pemanfaatan tumbuhan obat diperoleh dari nenek moyang dan diwariskan dari generasi kegenerasi, sehingga untuk mengetahui pengetahuan mengenai pemanfaatan tumbuhan obat masih terjaga atau mengalami penurunan maka dilakukan penyebaran angket terhadap 20 orang masyarakat Suku Dayak Lundayeh (Tabel 1 dan Tabel 2).

Tabel 1. Pengetahuan Generasi muda (15-35 tahun)

\begin{tabular}{|c|c|c|c|c|c|}
\hline \multirow[b]{2}{*}{ Nama lokal } & \multirow[b]{2}{*}{ Nama tumbuhan } & \multicolumn{4}{|c|}{ Persentase $(\%)$} \\
\hline & & $\begin{array}{c}\text { Pernah } \\
\text { Mende- } \\
\text { ngar }\end{array}$ & $\begin{array}{l}\text { Pernah } \\
\text { melihat }\end{array}$ & $\begin{array}{l}\text { Pernah } \\
\text { mengkon- } \\
\text { sumsi }\end{array}$ & $\begin{array}{c}\text { Pernah } \\
\text { mengguna- } \\
\text { kan sebagai } \\
\text { obat }\end{array}$ \\
\hline Babas & Kalanchoe Pinnata (Lam.) Pers. & 40 & 10 & - & 10 \\
\hline Bua Lade’ & Capsicum frutescens L. & 100 & 100 & 100 & - \\
\hline Duli’ & Homalomena sp. & 100 & 30 & - & 20 \\
\hline Geri Sarang & Ixora Coccinea $\mathrm{L}$. & 100 & 100 & - & - \\
\hline Ipung & Blumea balsamifera DC. & 50 & 10 & - & - \\
\hline Iyur kuda & Stacytarpheta jamaicensis (L.) Vahl. & 20 & - & - & - \\
\hline $\begin{array}{l}\text { Kumis } \\
\text { Kucing }\end{array}$ & Orthosiphon spicatus B.B.S. & 100 & 100 & - & - \\
\hline Kunus & Curcuma longa $\mathrm{L}$. & 100 & 100 & 90 & - \\
\hline $\begin{array}{l}\text { Liye' } \\
\text { budak }\end{array}$ & Curcuma zedoaria (Berg.) Rosc. & - & - & - & - \\
\hline Liye' bun & Curcuma xanthorrhiza Roxb. & 100 & 90 & 50 & 10 \\
\hline Liye' fasut & Zingiber aromaticum Val. & 30 & - & - & - \\
\hline Liye' siya & Zingiber officinnale Rosc. & 100 & 100 & 60 & 60 \\
\hline Liye' item & Curcuma aeruginosa Roxb. & - & - & - & - \\
\hline Liye' lisit & Curcuma mangga Val. & - & - & - & - \\
\hline Pecah beling & Strobilanthes crispus BI. & 90 & 30 & - & - \\
\hline $\begin{array}{l}\text { Rumput } \\
\text { gendong anak }\end{array}$ & Phyllanthus niruri L. & 40 & 10 & - & 10 \\
\hline Saga & Cassia alata $\mathrm{L}$. & 100 & 100 & - & 30 \\
\hline Sesila' & Carica papaya $\mathrm{L}$ & 100 & 100 & 100 & - \\
\hline $\begin{array}{l}\text { Tabar } \\
\text { Kedayan }\end{array}$ & Aristolochia foveolata Merr. & 100 & 80 & - & - \\
\hline Udu' buen & Ageratum conyzoides L. & 20 & - & - & - \\
\hline Udu’saku & Eclipta sp. & 90 & 90 & - & 20 \\
\hline
\end{tabular}

Tabel 2. Pengetahuan Generasi Tua (> 36 tahun)

\begin{tabular}{llcccc}
\hline & & \multicolumn{2}{c}{ Persentase (\%) } \\
\cline { 3 - 6 } Nama lokal & \multicolumn{1}{c}{ Nama tumbuhan } & $\begin{array}{c}\text { Pernah } \\
\text { Mende- } \\
\text { ngar }\end{array}$ & $\begin{array}{c}\text { Pernah } \\
\text { melihat }\end{array}$ & $\begin{array}{c}\text { Pernah } \\
\text { mengkon- } \\
\text { sumsi }\end{array}$ & $\begin{array}{c}\text { Pernah } \\
\text { mengguna- } \\
\text { kan sebagai } \\
\text { obat }\end{array}$ \\
\hline Babas & Kalanchoe Pinnata (Lam.) Pers. & 100 & 90 & - & 30 \\
Bua Lade' & Capsicum frutescens L. & 100 & 100 & 90 & - \\
Duli' & Homalomena sp. & 100 & 100 & - & 100 \\
Geri Sarang & Ixora Coccinea L. & 100 & 100 & - & 40
\end{tabular}




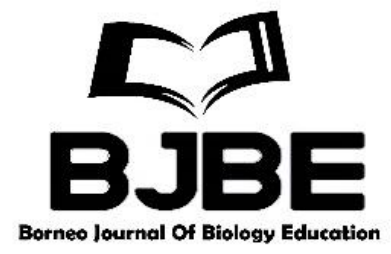

Vol. 2 No. 1, 2020; pp. 49-54

P-ISSN: 2715-6826 (print); E-ISSN: 2714-6073 (online)

Iyur kuda

Kumis

Kucing

Kunus

Liye'

budak

Liye' bun

Liye' fasut

Liye' siya

Liye' item

Liye' lisit

Pecah beling

Rumput

gendong anak

Saga

Sesila'

Tabar

Kedayan

Udu' buen

Blumea balsamifera DC.

Stacytarpheta jamaicensis (L.) Vahl.

Orthosiphon spicatus B.B.S.

Received: 12/07/2019

Revised: 09/08/2019

Accepted: 15/10/2019

Udu'saku

Curcuma longa $\mathrm{L}$.

Curcuma zedoaria (Berg.) Rosc.

Curcuma xanthorrhiza Roxb.

Zingiber aromaticum Val.

Zingiber officinnale Rosc.

Curcuma aeruginosa Roxb.

Curcuma mangga Val.

Strobilanthes crispus BI.

Phyllanthus niruri L.

Cassia alata L.

Carica papaya $\mathrm{L}$.

Aristolochia foveolata Merr.

$\begin{array}{cccc}90 & 60 & - & 20 \\ 10 & 10 & - & - \\ 100 & 100 & - & 50 \\ 100 & 100 & 100 & 100\end{array}$

20

50

100

$\begin{array}{llll}100 & 100 & 40 & 40\end{array}$

$\begin{array}{llll}70 & 20 & - & -\end{array}$

$100 \quad 100$

- $\quad-$

10

80

$-$

40

$\begin{array}{llll}100 & 100 & - & 60\end{array}$

$\begin{array}{llll}100 & 100 & - & 50\end{array}$

$\begin{array}{llll}100 & 100 & 100 & 20\end{array}$

$\begin{array}{llll}100 & 100 & - & 50\end{array}$

Ageratum conyzoides L.

Eclipta sp.

30

100

100

60

Uji Man-whitney dilakukan untuk mengetahui perbedaan pengetahuan masyarakat Suku Dayak Lundayeh mulai dari generasi muda sampai generasi tua terkait tumbuhan obat yang diperoleh dari skor angket yang diberikan kepada masyarakat (Tabel 3).

Tabel 3. Skor Angket Pemanfaatan Tumbuhan Obat

\begin{tabular}{ccc}
\hline No & Generasi Muda & Generasi Tua \\
\hline 1 & 6,75 & 9 \\
2 & 7,25 & 12,25 \\
3 & 7,75 & 10,5 \\
4 & 7,75 & 11,25 \\
5 & 7,75 & 8,25 \\
6 & 6,75 & 7,25 \\
7 & 5,75 & 7,25 \\
8 & 9 & 11,25 \\
9 & 8,25 & 9,25 \\
10 & 7,75 & 9 \\
\hline
\end{tabular}

Tabel 4. Mann Whitney Test

\section{Ranks}

\begin{tabular}{|c|c|c|c|c|}
\hline & Usia & $\mathrm{N}$ & Mean Rank & Sum of Ranks \\
\hline \multirow[t]{3}{*}{ Skor } & 15-35 tahun & 10 & 13,95 & 139,50 \\
\hline & $>36$ tahun & 10 & 7,05 & 70,50 \\
\hline & total & 20 & & \\
\hline
\end{tabular}

Test Statistics $^{\mathrm{a}}$

\begin{tabular}{ll}
\hline & Skor \\
\hline Mann-Whitney U & 15.500 \\
Willcoxon W & 70.500 \\
$\mathrm{Z}$ & -2.629 \\
Asymp. Sig (2-tailed) & .009 \\
Exact Sig. [2*(1-tailed Sig.)] & .007 \\
\hline
\end{tabular}




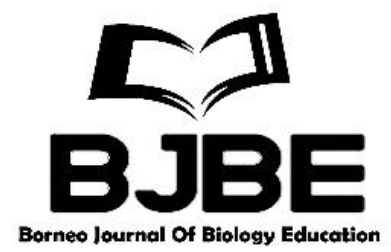

Hasil uji Man-whitney yang diperoleh dari skor angket yang diberikan kepada masyarakat, diketahui nilai signifikansi (Asym Sig) adalah 0,009. Karena signifikansi $<0,05$ maka dapat disimpulkan bahwa ada perbedaan pengetahuan antara generasi muda (15-35 tahun) dengan generasi tua (> 36 tahun) mengenai pemanfaatan tumbuhan obat.

Pewarisan pengetahuan tradisional mengenai tumbuhan obat sudah menurun dari generasi ke generasi (Tabel 3). Penurunan pewarisan pengetahuan tradisional diduga disebabkan oleh masuknya era modern seperti kemajuan teknologi dalam kehidupan seharihari masyarakatnya. Attamimi (1997) menyatakan bahwa peningkatan kemajuan teknologi dan ilmu pengetahuan mengakibatkan generasi muda meninggalkan kebudayaannya sendiri dan lebih tertarik pada produk-produk diluar kebudayaannya. Selain itu, Sada dan Tanjung (2010) menyatakan bahwa salah satu faktor yang dapat mempengaruhi pewarisan pengetahuan tradisional mengenai tumbuhan obat adalah persepsi generasi muda mengenai tumbuhan obat tradisional yang dianggap tidak praktis karena memerlukan waktu untuk mencari dan mengolahnya sehingga mereka lebih tertarik pada obat-obat modern.

\section{Kesimpulan}

Terdapat perbedaan pengetahuan antara generasi muda dan generasi tua terkait tumbuhan obat. Berdasarkan data yang diperoleh generasi tua setidaknya masih menggunakan 12 spesies tumbuhan obat dalam kehidupan sehari-hari. Sementara generasi muda hanya menggunakan 7 spesies.

\section{Daftar Pustaka}

Metananda, A.A,. (2012).Etnobotani Pangan dan Obat Masyarakat Sekitar Taman Nasional Gunung (Studi Kasus Pada Suku Sasak di Desa Jeruk Manis, Kecamatan Sikur, Kabupaten Lombok Timur, Nusa Tenggara Barat).Skripsi,Jurusan Konservasi Sumberdaya, Fakultas Kehutanan, Institut Pertanian Bogor.

Syukur, R., Alam, G., Mufidah, A. R., \& Tayeb, R. (2011). Aktivitas Antiradikal Bebas Beberapa Ekstrak Tanaman Familia Fabaceae. JST. Kesehatan, 1(1), 1411-1674.

Ilhadi, I. (2016). Pengobatan Tradisional Di Nagari Toboh Ketek, Kecamatan Enam Lingkung, Kabupaten Padang Pariaman Studi Kasus: Ayam Sebagai Media Mengidentifikasi Penyakit (Doctoral dissertation, Universitas Andalas).

Rahman, S. A., \& Kasniyah, N. (2013). Kajian Etnomedisin pada Orang Tugutil di Halmahera: Sistem Personalistik dan Naturalistik (Doctoral dissertation, [Yogyakarta]: Universitas Gadjah Mada).

Ani, N., Rohyani, I. S., \& Ustadz, M. (2018). Pengetahuan Masyarakat Tentang Jenis Tumbuhan Obat Di Kawasan Taman Wisata Alam Madapangga Sumbawa. Jurnal Pijar Mipa, 13(2), 160-166.

Atmojo, S. E. (2013). Pengenalan Etnobotani Pemanfaatan Tanaman Sebagai Obat Kepada Masyarakat Desa Cabak Jiken Kabupaten Blora. Jurnal Ilmiah WUNY, 15(1). 
Setiawan, A., Listiani, L., \& Abrori, F. M. (2019). Kajian Etnobotani Tumbuhan Obat Suku Dayak Lundayeh Di Desa Kaliamok Kecamatan Malinau Utara Kabupaten Malinau Sebagai Booklet Untuk Masyarakat. Borneo Journal of Biology Education, 1(1), 51-67.

Suryadharma, IGP. (2008). Diktat Kuliah Etnobotani Universitas Negeri Yogyakarta.

Nurraini, L dan Tabba, S. (2013). Persepsi dan Ketergantungan Masyarakat terhadap Sumber Daya Alam Taman Nasional Aketajawe Lolobat di Provinsi Maluku Utara. Jurnal Penelitian Sosial dan Ekonomi Kehutanan 10 (1): 61-73.

Attamimi, F. (1997). Pengetahuan Masyarakat Suku Mooi Tentang Pemanfaatan Sumberdaya Nabati Di Dusun Maibo Desa Aimas Kabupaten Sorong. Skripsi (Tidak dipublikasikan) Universitas Cenderawasih Manokwari.

Sada, J,T dan Tanjung, R,H,R. (2010). Keragaman Tumbuhan Obat Tradisional Di Kampung Nansfori Distrik Supiori Utara, Kabupaten Supiori-Papua. Jurnal Biologi Papua 2 (2): $39-46$ 